\title{
Designing of high value-added pasta formulas by incorporation of grape pomace skins
}

\author{
CRISTINA GAITA ${ }^{1}$, ERSILIA ALEXA ${ }^{1}$, DIANA MOIGRADEAN ${ }^{1}$, FILOMENA \\ CONFORTI $^{2}$, MARIANA-ATENA POIANA ${ }^{1}$,*
}
${ }^{1}$ Banat's University of Agricultural Sciences and Veterinary Medicine "King Michael I of Romania" from Timisoara, Faculty of Food Engineering, Calea Aradului 119, Timisoara 300645, Romania ${ }^{2}$ University of Calabria, Department of Pharmacy, Health and Nutritional Sciences, via Pietro Bucci - Edificio Polifunzionale, 87036 Arcavacata di Rende (CS), Italy

\begin{abstract}
The purpose of this study was to design pasta formulas with improved antioxidant and sensory properties by addition of grape pomace skins (GPS) coming from winemaking of Pinot Noir and Italian Riesling grapes. The grape skins, separated from dried pomace, were used in the pasta recipe by replacement of wheat flour in proportion of 3,6 and $9 \%(\mathrm{w} / \mathrm{w})$. The pasta samples were analyzed in terms of polyphenolic compounds by liquid chromatography-mass spectrometry, total phenolics content, antioxidant capacity and sensory properties. Our data revealed that phenolic compounds such as gallic, ferulic, coumaric, rosmarinic, and caffeic acid were identified in the analyzed samples. Additionally, epicatechin, rutin, quercetin, kaempferol and resveratrol have been found in the pasta formulas. It has also been noticed improvements in the polyphenolic content by increasing the percentage of GPS. Our results suggest that the antioxidant capacity of fortified pasta samples was increased by incorporation of polyphenols from GPS. Moreover, it was found that the incorporation of GPS up to a level of $6 \%$ into the pasta formulation led to obtaining of products with improved sensory and functional properties. These findings demonstrate that it is possible to valorize the winery wastes to develop innovative value-added pasta formulas.
\end{abstract}

Keywords Grape pomace skins, pasta formulas, phenolic compounds, total antioxidant capacity, sensory properties.

To cite this article: GAITA C, ALEXA E, MOIGRADEAN D, CONFORTI F, POIANA M-A. Designing of high value-added pasta formulas by incorporation of grape pomace skins. Rom Biotechnol Lett. 2020; 25(3): 1607-1614. DOI: 10.25083/rbl/25.3/1607.1614

$\triangle$ *Corresponding author: MARIANA-ATENA POIANA, Banat's University of Agricultural Sciences and Veterinary Medicine "King Michael I of Romania" from Timisoara, Calea Aradului 119, 300645, Romania

E-mail: atenapoiana@yahoo.com 


\section{Introduction}

The grape pomace represents a valuable by-product generated in very high quantity during the winemaking, consisting of seeds, skins and stalk fragments (SUI \& al [1]). The generation of wastes in the wine production is about of $18 \mathrm{~kg}$ of grape pomace for every $100 \mathrm{~L}$ of wine (ROCKENBACH \& al [2]). Nowadays, the food industry is continuously searching for new value-added ingredients derived from the wastes generated by agro-food processing. The grape pomace represents a valuable source of biologically active species, such as antioxidant polyphenols, a low-cost raw material for extraction of value-added compounds used as potential functional food ingredients, especially food additives or nutraceuticals. Thus, grape pomace has been suggested as functional ingredient to develop healthy foods for the prevention of diet related disease (TEIXEIRA \& al [3]). The incorporation of grape pomace in the food products can help to reduce certain nutritional issues identified in western societies, such as a weak content of antioxidants, fibers and minerals (FLAGG \& al [4]; HE \& MAC GREGOR [5]; SLAVIN [6]).

The number of published works on incorporation the grape pomace in food products has markedly grown since 2010, with applications that mostly describe the improving in the dietary fiber and phenolic compounds content as well as the antioxidant effects (GARCÍA-LOMILLO \& al [7]).

Several food classes have been successfully enriched in phenols by incorporating wine pomace products. Cereal products, mainly bread, biscuits, cookies and pasta are the category with the highest number of applications of wine pomace flour. In this purpose, the grape pomace was incorporated into bakery products as the partial replacement of flour, because the grape pomace flour is gluten-free and represents a rich source of dietary fibers (GARCÍALOMILLO \& al [7]). It has been evaluated the effect of grape pomace addition in sourdough rye bread, at a level ranged from 4 to $10 \%$ on soluble and insoluble dietary fiber content, phenolic compounds, antioxidant activity and organoleptic characteristics of obtained bread (MILDNERSZKUDLARZ \& al [8]). In the study performed by BAIANO \& al [9] it has been investigated the production of functional bread by replacing water with phenolic aqueous extracts obtained by microwave-assisted extraction from vegetable wastes including grape marc. The research performed by MANER \& al [10] evaluated the possibility to fortify cookies by replacing the wheat flour with grape marc in the range $5-20 \%(\mathrm{w} / \mathrm{w})$. Also, the grape seed flour from winery waste was included in cereal bars and pancakes to improve their antioxidant properties (ROSALES SOTO \& al [11]). A recent study on this topic established the optimum dose of grape skin flour that can be incorporated in bakery products for obtaining acceptable products in terms of rheological characteristics, with improved nutritional and functional properties (OPREA $\&$ al [12]).

Available studies on this topic have shown that the grape pomace can be used as a functional ingredient in other classes of food products such as tomato puree
(LAVELLI \& al [13]), seafood and sauces (RIBEIRO \& al [14]), tea infusion (BEKHIT \& al [15]) and candies (CAPPA \& al [16]).

It has been also evaluated the feasibility to use grape pomace as an alternative source of antioxidant dietary fibers for enhancing the nutritional value and extending the shelf life of yogurt and salad dressing (TSENG \& ZHAO [17]) as well as chopped fish muscle (SANCHEZALONSO \& al [18]). In the same line of research, the study performed by RABABAH \& al [19] investigated the effectiveness to use the grape seed extract as a natural antioxidant for preserving the extruded corn chips during storage.

Pasta is a traditional cereal-based product with a relatively long shelf life, being considered a suitable matrix for addition of functional ingredients because it is accepted worldwide due to low cost, easy production and sensory attributes (CHILLO \& al [20]).

So far, there are limited studies regarding the use of grape pomace products as an alternative source of phenolic compounds for designing novel pasta formulas. In the research performed by SANT'ANNA \& al [21], a part of wheat flour from the recipe of the fettuccini pasta was replaced by grape marc powder at different levels $(25,50$ and $75 \mathrm{~g} / \mathrm{kg}$ ), and the results shown that the incorporation of grape marc powder increased the total phenolics, condensed tannins, monomeric anthocyanins and antioxidant capacity. In other study, MARINELLI \& al [22] exploited the potential of wine pomace by obtaining an aqueous ultrasound-assisted extract that has been further used to prepare spaghetti formulas enriched with grape marc extract. The obtained products showed increased total phenolics and flavonoids content as well as higher antioxidant capacity than the control sample. The grape pomace skins powder contains bioactive compounds such as polyphenols, flavonols, resveratrol and dietary fibers being recommended as a nutritional supplement in the bakery industry (OPREA \& al [12]).

In line with the above mentioned data, the purpose of our study represents an attempt to exploit the potential of grape pomace skins coming from winemaking of Pinot Noir and Italian Riesling grape varieties to develop new pasta formulas with improved functionality.

\section{Materials and Methods}

\section{Grape pomace conditioning}

The grape pomace resulted as main by-product in the winemaking of Pinot Noir (PN) and Italian Riesling (IR) grape varieties was collected from western Romania (Teremia Mare Winery, Timis County) and conditioned by drying in a forced air oven (Froilabo AC60/France, $1000 \mathrm{~W}$ ) at $60^{\circ} \mathrm{C}$ for $8 \mathrm{~h}$ daily, three days in a row, to avoid a significant degradation of the bioactive compounds. The grape pomace skins (GPS), manually separated from the conditioned grape pomace, were ground using the laboratory mill Grindomix Retsch GM 2000, passed through a 60 mesh sieve and further, the resulted powder was used as a functional ingredient in the pasta formulation. 


\section{Pasta preparation}

The GPS at a level of 3, 6 and 9\% (w/w) has been used as ingredient in the pasta recipe alongside wheat flour type 550 and eggs, by corresponding replacement of the wheat flour in the mentioned percentages. Thus, six pasta formulas fortified with GPS derived from PN and IR grape marc were obtained, as follows: $\mathrm{P}+3 \% \mathrm{PN}, \mathrm{P}+6 \% \mathrm{PN}$, $\mathrm{P}+9 \% \mathrm{PN}, \mathrm{P}+3 \% \mathrm{IR}, \mathrm{P}+6 \% \mathrm{IR}$ and $\mathrm{P}+9 \% \mathrm{IR}$. Additionally, a control pasta sample (C), without GPS addition has been prepared. The pasta pre-drying has been performed with air in the convection oven (Esmach, Italy, $1200 \mathrm{~W}, 50 \mathrm{~Hz}$ ) at a temperature of $30-35^{\circ} \mathrm{C}$ while the drying was carried out at a temperature of $40-55^{\circ} \mathrm{C}$. The moisture content recorded in pasta samples ranged from initial values of 29.0-32.5\% to final values below $13.0 \%$. The dried pasta samples were kept in paper bags, in a storage room, in the dark, at a temperature of $15-18^{\circ} \mathrm{C}$ and a relative humidity of $60-65 \%$ for 1 week prior analysis.

\section{Extraction of polyphenolic compounds}

The extraction of polyphenolic compounds from grinded pasta samples was performed in hydroalcoholic medium with ethanol $45 \%(\mathrm{v} / \mathrm{v})$ at a ratio solid:solvent of 1:20 under stirring for $1 \mathrm{~h}$, at a temperature of $25^{\circ} \mathrm{C}$ using the horizontal shaker Heidolph Promax 1020 (Germany). The mixtures were filtered and the obtained clear fractions were further used for analysis.

\section{LC-MS Analysis of polyphenolic compounds}

The separation and identification of non-anthocyanin polyphenols was performed by liquid chromatographymass spectrometry technique (LC-MS). It was used the Shimadzu LCMS-2010 EV system (Shimadzu, Kyoto, Japan) with electrospray ionization (ESI). In this system, the HPLC unit equipped with a UV-VIS spectrophotometer detector (SPD-10A), a degasser, an auto sampler and solvent delivery pumps (LC-10AD) is in-line connected with a mass spectrometer (MS-2010). The reversed-phase separation was performed on an EC 150/2 NUCLEODUR C18 Gravity SB $150 \mathrm{~mm} \times 2.0 \mathrm{~mm}$ column, particle size $5 \mu \mathrm{m}$ (Macherey-Nagel GmbH \& Co. KG, Germany) following the protocol described by ABDEL-HAMEED $\&$ al [23]. The compounds were separated with gradient elution of $\mathrm{A}$ (aqueous formic acid, $\mathrm{pH}=3$ ) and $\mathrm{B}$ (solution of acetonitrile and formic acid, $\mathrm{pH}=3$ ). The gradient program was: $5 \% \mathrm{~B}$ (0.01-20 min), 5-40\% B (20.01-50 min, $10 \mathrm{~min}$ ), 40-95\% B (50-55 min), 95\% B (55-60 min). The solvent flow rate was $0.2 \mathrm{~mL} / \mathrm{min}$ and the temperature $20^{\circ} \mathrm{C}$. The monitoring was performed at 280 and $320 \mathrm{~nm}$ and the diode array detector was set at an acquisition range from 200 to $700 \mathrm{~nm}$. The spectral acquisition rate was $1.25 \mathrm{scans} / \mathrm{s}$ (peak width $0.2 \mathrm{~min}$ ). The calibration curves for each individual compound were performed in the range $20-50 \mu \mathrm{g} / \mathrm{mL}$ by plotting the peak area versus concentration. The compounds were identified based on retention times (RT) and mass/charge ratio $(\mathrm{m} / \mathrm{z})$ of ions of interest, as follows: gallic acid (RT: $5.1, \mathrm{~m} / \mathrm{z}$ : 169), caffeic acid (RT: $21.2 \mathrm{~min}, \mathrm{~m} / \mathrm{z}: 179$ ), epichatechin (RT: $22.8 \mathrm{~min}$, $\mathrm{m} / \mathrm{z}$ : 289), coumaric acid (RT: $24.4 \mathrm{~min}, \mathrm{~m} / \mathrm{z}$ : 163), ferulic acid (RT: $23.6 \mathrm{~min}, \mathrm{~m} / \mathrm{z}: 193$ ), rutin (RT: $25.9 \mathrm{~min}, \mathrm{~m} / \mathrm{z}$ : 609), rosmarinic acid (RT: $27.2 \mathrm{~min}, \mathrm{~m} / \mathrm{z}: 359)$, resveratrol (RT: $30.1 \mathrm{~min}, \mathrm{~m} / \mathrm{z}: 227$ ), quercetin (RT: $31.3 \mathrm{~min}, \mathrm{~m} / \mathrm{z}$ : 301), kaempferol (RT: $33.6 \mathrm{~min}, \mathrm{~m} / \mathrm{z}$ : 285). The limit of detection (LOD), representing the amount of compounds that could be detected with a signal to noise ratio $(\mathrm{S} / \mathrm{N}) \geq 3$, was $0.3 \mu \mathrm{g} / \mathrm{mL}$ for all identified polyphenolic compounds. Also, the limit of quantification (LOQ), representing the lowest concentration for which $\mathrm{S} / \mathrm{N} \geq 5$, was $0.5 \mu \mathrm{g} / \mathrm{mL}$. The Shimadzu LC Solutions software has been used for data acquisition, peak integration and calibrations. The analyses were performed in triplicate and the results, expressed in $\mu \mathrm{g} / \mathrm{g}$ dry substance (d.s), are reported as means \pm standard deviation. All the used reagents and solvents were of analytical grade purity.

\section{Evaluation of total phenolics content}

The total phenolics (TP) content in the pasta samples was assessed following the Folin-Ciocalteu colorimetric method described by SINGLETON \& al [24]. The determination TP content was performed on the same extracts used in the LC-MS Analysis of polyphenols. The absorbance was measured at a wavelength of $750 \mathrm{~nm}$ and the gallic acid was used as a standard. All determinations were carried out in triplicates and the results, expressed as mg gallic acid equivalents $(\mathrm{GAE}) / \mathrm{g}$ d.s were reported as average value \pm standard deviation.

\section{Evaluation of total antioxidant capacity}

The antioxidant capacity of pasta samples was evaluated by spectrophotometric FRAP (ferric reducing antioxidant power) assay (BENZIE \& STRAIN [25]; POIANA \& al [26]). The analysis was performed on the same extracts used for TP content evaluation. This method allows the assessing of the samples ability to reduce the ferric 2,4,6-tris(2-pyridyl)-1,3,5-triazine (TPTZ) complex to ferrous form which is blue-colored in sodium acetate buffer of $\mathrm{pH} 3.6$ at a temperature of $37^{\circ} \mathrm{C}$. The changes recorded in the absorbance value were monitored at a wavelength of $593 \mathrm{~nm}$ using the UV-VIS spectrophotometer Analytic Jena SPECORD 205. The determinations were performed in triplicates and the results (FRAP values), expressed as $\mu \mathrm{M} \mathrm{Fe}{ }^{2+} / g$ d.s, were reported as average value \pm standard deviation.

\section{Sensory analysis of pasta samples}

The sensory analysis of the pasta had been performed using the 20 point scale method according to STAS 756/ 1-85 [27]. Each sensory attribute was evaluated by a group of 10 tasters and then, the group leader calculated the average equal score for each sensory feature by multiplying the unmatched average score with weight score (one decimal point and no rounding is used on calculations). The weighting factor for each characteristic is shown in the Table 1. The organoleptic quality level of the product is established on the basis of total score, as follows: 18.00-20.0 points (very good), 15.2-17.9 (good), 11.2-15.1 (satisfying), 7.1-11.1 (unsatisfying), 4.1-7.0 (bad) and 0-4.0 (very bad). 
Table 1. The weighting factor for sensory attributes [27]

\begin{tabular}{|c|c|}
\hline Sensory attribute & Weighting factor \\
\hline Exterior appearance and color & 1.0 \\
\hline Behavior at boiling & 0.6 \\
\hline Smell and taste & 1.6 \\
\hline Foreign bodies & 0.4 \\
\hline Infestation & 0.4 \\
\hline
\end{tabular}

\section{Statistical analysis}

The statistical $\mathrm{d}$ ata processing has been performed by one-way analysis of variance (ANOVA) using Statistical Analysis System (SAS) [28]. Computations Tukey posthoc means comparisons was included to evaluate the statistical significance of the differences between the group means. Conventionally the $5 \%, 1 \%$ and $0.1 \%(\mathrm{P}<0.05,0.01$ and 0.001) significance levels have been used, where $\mathrm{P}$ - value is the probability value. Statistical differences are indicated versus the control sample, as follows: ns - non-significant, $\mathrm{P}>0.05 ;^{*}-$ significant, $\mathrm{P}<0.05$; ${ }^{* *}$ - highly significant, $\mathrm{P}<0.01$ and $^{* * *}$ - extremely significant, $\mathrm{P}<0.001$.

\section{Results and Discussion}

\section{Polyphenolic compound identified in the pasta formulas}

The results obtained following the LC-MS analysis of the polyphenolic compounds of the extracts obtained from pasta samples have been shown in the Table 2. It can be seen that gallic, caffeic, coumaric, ferulic and rosmarinic acid were the main phenolic acids identified in the pasta formulas. In addition, various phenolic compounds such as epichatechin, rutin, quercetin, resveratrol and kaempferol have also been identified. Our results are consistent with data available on this topic reported by GENGAIHI \& al [29]. On the base of data shown in the Table 2 it can be noticed that the gallic and ferulic acid have been identified only in the samples with GPS originated from PN, the highest values being reached in samples with a level of 9\% PN (gallic acid: $82.22 \mu \mathrm{g} / \mathrm{g}$ d.s and ferulic acid: $15.75 \mu \mathrm{g} / \mathrm{g}$ d.s). Caffeic acid has been found in both the control sample and all pasta samples with GPS, the highest concentration being in the sample with a level of $9 \%$ IR $(58.11 \mu \mathrm{g} / \mathrm{g} \mathrm{d} . \mathrm{s})$. Also, the coumaric acid and epicatechin have been identified both in all pasta samples, the highest concentrations being reached in the sample with a level of $9 \% \mathrm{PN}$ (epicatechin: $44.34 \mu \mathrm{g} / \mathrm{g}$ d.s and coumaric acid $17.45 \mu \mathrm{g} / \mathrm{g}$ d.s). The resveratrol has not been detected in the control sample. It has been found only in the pasta samples fortified with GPS, the highest level being reached in the formula with $9 \% \mathrm{PN}(70.73 \mu \mathrm{g} / \mathrm{g}$ d.s $)$.

Table 2. Polyphenolic compounds identified in the pasta samples

\begin{tabular}{|c|c|c|c|c|c|}
\hline Sample & \multicolumn{5}{|c|}{ Polyphenolic compounds ( $\mu \mathrm{g} / \mathrm{g}$ d.s) } \\
\hline & Gallic acid & Caffeic acid & Epichatechin & Coumaric acid & Ferulic acid \\
\hline C & ND & $0.66 \pm 0.03$ & $10.29 \pm 0.25$ & $0.32 \pm 0.01$ & ND \\
\hline $\mathbf{P + 3 \%} \mathbf{P N}$ & $27.95 \pm 0.73^{* * *}$ & $3.76 \pm 0.12^{* * * *}$ & $24.78 \pm 0.67^{* * * *}$ & $8.16 \pm 0.24^{* * *}$ & $6.33 \pm 0.19^{* * *}$ \\
\hline $\mathrm{P}+6 \% \mathrm{PN}$ & $52.89 \pm 1.27^{* * * *}$ & $5.67 \pm 0.18^{* * *}$ & $37.82 \pm 0.98^{* * * *}$ & $13.83 \pm 0.37^{* * *}$ & $10.27 \pm 0.27^{* * *}$ \\
\hline $\mathbf{P}+9 \% \mathbf{P N}$ & $82.22 \pm 1.75^{* * *}$ & $9.32 \pm 0.27^{* * *}$ & $44.34 \pm 1.15^{\text {**** }}$ & $17.45 \pm 0.47^{* * *}$ & $15.75 \pm 0.41^{* * *}$ \\
\hline P+3\%IR & ND & $13.63 \pm 0.35^{\text {*** }}$ & $10.57 \pm 0.27^{\mathrm{ns}}$ & $0.47 \pm 0.01^{\mathrm{ns}}$ & ND \\
\hline P+6\%IR & ND & $34.18 \pm 0.81^{* * * *}$ & $11.68 \pm 0.31^{\mathrm{ns}}$ & $0.66 \pm 0.02^{\mathrm{ns}}$ & ND \\
\hline P+9\%IR & ND & $58.11 \pm 1.16^{* * *}$ & $14.92 \pm 0.38^{* * * *}$ & $0.85 \pm 0.03^{\mathrm{ns}}$ & ND \\
\hline Sample & Rutin & $\begin{array}{c}\text { Rosmarinic } \\
\text { acid }\end{array}$ & Resveratrol & Quercetin & Kaempferol \\
\hline C & $7.83 \pm 0.20$ & $26.1 \pm 0.68$ & ND & $2.89 \pm 0.09$ & $19.73 \pm 0.51$ \\
\hline $\mathrm{P}+3 \% \mathrm{PN}$ & $0.14 \cdot 10^{3} \pm 3.64^{* * *}$ & $27.13 \pm 0.71^{\mathrm{ns}}$ & $31.15 \pm 1.24^{* * * *}$ & $3.8 \pm 0.10^{\mathrm{ns}}$ & $0.18 \cdot 10^{3} \pm 4.53^{* * *}$ \\
\hline $\mathrm{P}+6 \% \mathrm{PN}$ & $0.25 \cdot 10^{3} \pm 6.25^{* * *}$ & $29.34 \pm 0.76^{* *}$ & $52.75 \pm 2.16^{\text {*** }}$ & $5.6 \pm 0.14^{\mathrm{ns}}$ & $0.34 \cdot 10^{3} \pm 8.84^{* * * *}$ \\
\hline $\mathrm{P}+9 \% \mathrm{PN}$ & $0.37 \cdot 10^{3} \pm 9.62^{* * * *}$ & $33.18 \pm 0.83^{* * * *}$ & $70.43 \pm 2.69^{* * *}$ & $7.3 \pm 0.18^{\mathrm{ns}}$ & $0.51 \cdot 10^{3} \pm 12.75^{* * *}$ \\
\hline P+3\%IR & $9.71 \pm 0.26^{\mathrm{ns}}$ & $28.64 \pm 0.72^{*}$ & $14.27 \pm 0.47^{* * * *}$ & $0.09 \cdot 10^{3} \pm 2.34^{* * * *}$ & $30.63 \pm 0.77^{\mathrm{ns}}$ \\
\hline P+6\% IR & $14.48 \pm 0.36^{\mathrm{ns}}$ & $32.2 \pm 0.84^{* * *}$ & $23.74 \pm 0.85^{\text {**** }}$ & $0.15 \cdot 10^{3} \pm 3.75^{* * * *}$ & $37.48 \pm 0.94^{*}$ \\
\hline P+9\%IR & $18.56 \pm 0.48^{\mathrm{ns}}$ & $38.53 \pm 0.96^{* * *}$ & $34.38 \pm 1.27^{\text {**** }}$ & $0.22 \cdot 10^{3} \pm 5.6^{* * *}$ & $54.24 \pm 1.36^{* * *}$ \\
\hline
\end{tabular}

ND - not detected; Statistical differences are shown in a column, versus control, as follows: ns - non-significant, $\mathrm{P}>0.05 ;{ }^{*}-$ significant, $\mathrm{P}<0.05 ;^{* *}-$ highly significant, $\mathrm{P}<0.01$ and ${ }^{* * *}-$ extremely significant, $\mathrm{P}<0.001$.

At a closer look on the data shown in Table 2 it can be seen that the fortification of pasta with GPS effectively enhanced the level of phenolic compounds. The recorded increases in the phenolic compounds content of fortified samples depends on the grape variety from which was originated GPS. Our findings are in agreement with those reported by RAMIREZ-LOPEZ \& DEWITT [30] who revealed that the differences in the polyphenolic compounds from dried grape pomace could vary depending on the grape variety, harvest time, maceration duration (for 
the black grapes), the pressing conditions used to separate the wine from the grape marc, the drying temperature of the marc and the extraction method of polyphenolic compounds. It has been found that the improvements in the content of polyphenols increases by increasing the GPS level from 3 to 6 and $9 \%$ but not in the same proportion. According to SWIECA \& al [31], the fortification of pasta with phenolic rich ingredients represents a successful technique which allows the increasing of TP content in pasta but the improvement with natural phenolics may be limited by many factors including the binding with food matrix components. The incorporation of functional materials with a high level of polyphenols induces significant changes in the relationships between the pasta components, affecting on bioactive ingredients bioavailability. The effectiveness of fortification and consequently the biological effect is limited by different types of interactions between phenolics and pasta proteins such as hydrogen bonding, ionic, covalent and hydrophobic. Also, other interactions phenolic-phenolic and phenolic-starch can occur. The strong affinity of phenolic compounds to bind with proteins from food matrix may lead to a decrease in their free levels, negative impacting on their bioavailability (SWIECA \& al [31]). Thus, the content of individual polyphenols depends on their affinity to bind with wheat flour proteins or other components of food matrix. In the light of this mention, the interaction of bioactive compounds with food matrix should be considered for designing of new functional foods.

The results of statistical processing by ANOVA test showed that the incorporation of GPS from PN to a level of 3, 6 and $9 \%$ in the pasta formulas induced extremely significant changes $(\mathrm{P}<0.001)$ in the gallic acid content versus the control sample. Also, the caffeic acid recorded extremely statistical significant changes $(\mathrm{P}<0.001)$ versus the control sample by fortification of pasta formulas with GPS. As regards the epicatechin content, there were no recorded significant changes $(\mathrm{P}>0.05)$ in the samples with GPS coming from IR at a level of 3 and $6 \%$ versus the control sample, while for all the other pasta samples were recorded extremely significant changes, versus the control sample $(\mathrm{P}<0001)$. The incorporation of GPS coming from $\mathrm{PN}$ induced extremely significant changes $(\mathrm{P}<0001)$ in the rutin, ferulic and coumaric acid content, versus the control sample. No significant changes $(\mathrm{P}>0.05)$ have been found versus the control in the content of these compounds for pasta samples with GPS originated from IR. The changes recorded in the rosmarinic acid versus the control have been become extremely significant $(\mathrm{P}<0.001)$ only for samples with addition of GPS from IR at a level of 6 and $9 \%$ as well as in the sample with $9 \%$ PN. No significant changes $(\mathrm{P}>0.05)$ have been found in the pasta sample with GPS coming from PN, added at a level of $3 \%$. It has been found that the incorporation of GPS from both grape varieties in the pasta formulas led to extremely significant changes $(\mathrm{P}<0.001)$ in the content of resveratrol versus the control sample. Also, the changes in the content of quercetin versus the control were extremely significant $(\mathrm{P}<0001)$ in samples with GPS coming from IR, while the incorporation of GPS from $\mathrm{PN}$ has not induced significant changes $(\mathrm{P}>0.05)$ at all concentrations. Concerning the kaempferol content, it can be seen that the incorporation of GPS in the pasta formulas led to extremely significant changes versus the control sample $(\mathrm{P}<0.001)$ for sample with $9 \%$ IR as well as for all samples with PN. There were no found significant changes $(\mathrm{P}>0.05)$ versus the control sample in the kaempferol content of the sample with GPS from IR at a level of $3 \%$. Also, our data reveal that only significant changes $(\mathrm{P}<0.05)$ versus the control have been recorded in pasta sample with $6 \%$ GPS coming from IR.

\section{Total phenolics content of the pasta formulas}

TP content of pasta formulas fortified by addition of GPS are depicted in the Figure 1. Our data reveal that the fortification of pasta with GPS had a positive effect on TP content. It can be observed important improvements in TP content by increasing the percentage of GPS. Thus, the incorporation of GPS originated from $\mathrm{PN}$ in the pasta recipe to a level of 3,6 and 9\% led to increases in TP content with 31,64 and $98 \%$ versus the control sample while the addition of GPS from IR resulted in increases of 39, 82 and $125 \%$, reported to the control sample.

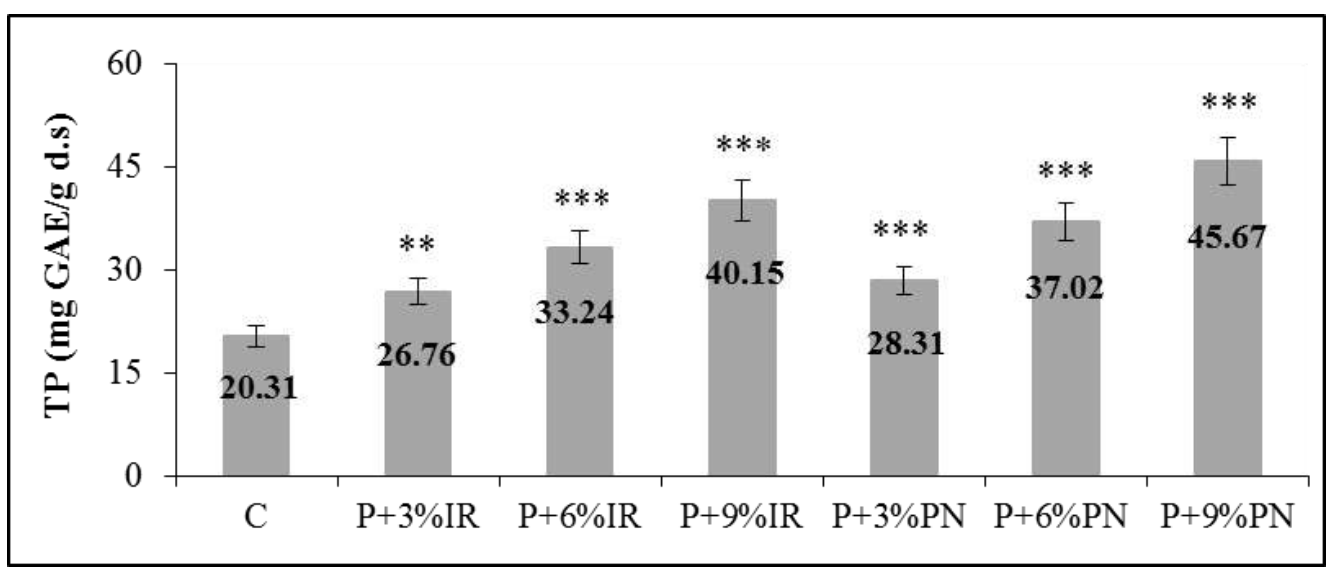

Figure 1. The effect of GPS addition on TP content of pasta formulas

Statistical differences are indicated versus the control sample, as follows:

${ }^{* *}$ - highly significant, $\mathrm{P}<0.01$ and $^{* * *}$ - extremely significant, $\mathrm{P}<0.001$. 
Our results are in agreement with data reported by SANT'ANNA \& al [21], which have revealed increases in TP content of fortified fettuccini samples with different doses of grape pomace powder. The statistical analysis by ANOVA test showed that the fortification of pasta with GPS induced extremely significant changes in TP content versus the control sample ( $\mathrm{P}<0001)$, except for sample with GPS originated from PN at a level of $3 \%$, where only highly significant changes $(\mathrm{P}<0.01)$ versus the control sample have been noted. The obtained data revealed that the improvements in TP content of pasta samples fortified with GPS originated from IR have been higher with $26-28 \%$ than those recorded for samples with addition of GPS coming from PN. This finding could be attributed to the different vinification techniques used for white and black grapes. Thus, the IR grape pomace was separated from the grape juice prior to winemaking, while PN grape pomace was separated after fermentation. The white grape skins coming from IR were not fermented, therefore, the most part of extractable substances remained in the grape pomace. Otherwise, the black grape skins originated from PN were fermented with the grape juice, so that, an important part of the extractable components, including polyphenolic compounds, passed up in the wine (DENG \& al [32]; XU $\&$ al [33]).

\section{Total antioxidant capacity of the pasta formulas}

The effect of pasta fortification with GPS originated from RI and PN on FRAP value are displayed in the
Figure 2. Our results indicate that the FRAP values of the pasta samples recorded important increases by increasing the level of GPS in the production recipe. By incorporation of GPS originated from PN to a level of 3,6 and 9\% in the pasta formulation, there were recorded increases in FRAP value of 28,69 and $110 \%$ relative to the control sample. The pasta samples fortified with GPS originated from IR were characterized by higher FRAP values than samples enriched with GPS from PN. Thus, the addition of GPS coming from IR to a level of 3,6 and 9\% led to increases in the FRAP value with 44,96 and $141 \%$ relative to the control sample. These results are in agreement with data reported by MARINELLI \& al [22] who observed an increase in the antioxidant capacity of spaghetti samples improved with grape marc extract. It could be suggested that the antioxidant capacity of the fortified pasta formulas increased due to the incorporation of polyphenols originated from GPS. As it has been reported by GENGAIHI $\&$ al [29], a high correlation was recorded between the antioxidant capacity and TP content. Our results are consistent with this finding, therefore, a strong positive correlation (the correlation coefficient $r=0.9978$ ) was detected between FRAP values and TP content of pasta samples, as it is shown in equation (1):

$$
\mathrm{FRAP}=-5.1714+1.5786 \cdot \mathrm{TP}
$$

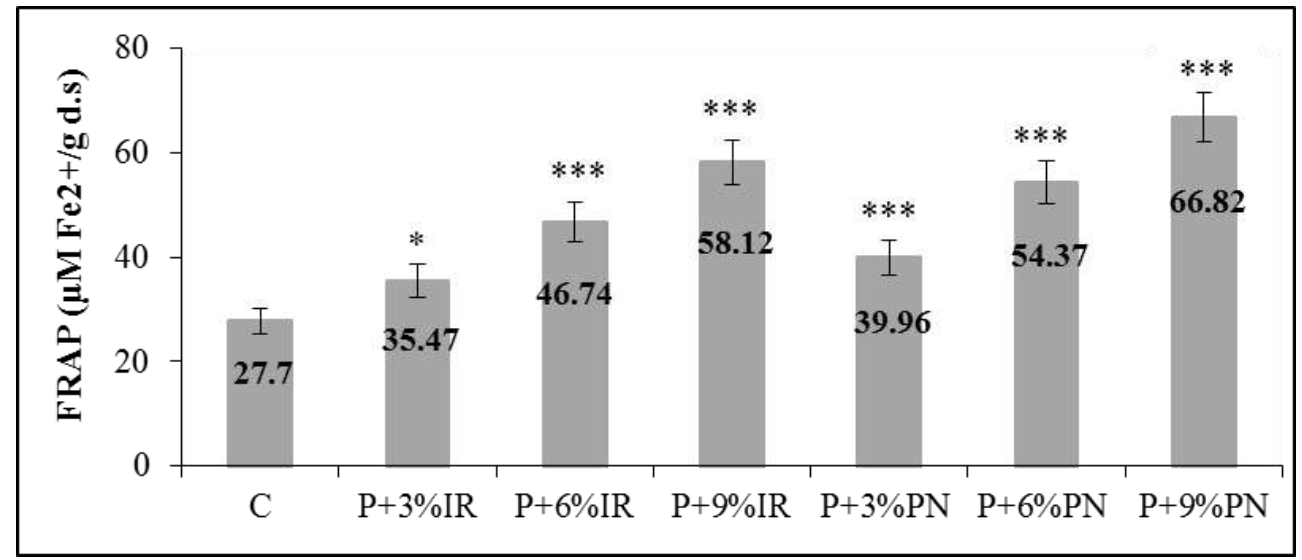

Figure 2. The effect of GPS addition on FRAP value of pasta formulas Statistical differences are indicated versus the control sample, as follows: ${ }^{*}$ - significant, $\mathrm{P}<0.05$ and ${ }^{* * *}$ - extremely significant, $\mathrm{P}<0.001$.

The results of the statistical analysis by the ANOVA test showed that the addition of GPS originated from PN to a level of $3 \%$ induced significant changes $(\mathrm{P}<0.05)$ in FPAP value versus the control sample. Instead, for all the other fortified pasta samples with GPS, there were recorded extremely significant changes in FPAP value, versus the control sample $(\mathrm{P}<0.001)$.

\section{Sensory properties of the pasta formulas}

As regards the sensory analysis of the pasta samples, the obtained data have been shown in the Table 3 . There are recorded differences in the sensory features of fortified pasta compared to the classic prototypes with which the consumer is accustomed. Our data showed that the pasta samples with addition of GPS to a level of 3 and $6 \%$ showed improved sensory characteristics versus the control sample. Moreover, the kneading and dough processing operations have not been affected at this level of GPS incorporation in the pasta formulas. The pasta formulas with addition of GPS originated from IR to a level of $3 \%$ have revealed the best sensorial properties, followed by samples with $6 \%$ IR, $3 \%$ PN and 6\% PN. Data reported by SANT'ANNA \& al [21] reveal that the incorporating of grape pomace powder in fettuccini at a level of $75 \mathrm{~g} / \mathrm{kg}$ led to a decrease in the 
consumer acceptance. The improvements noticed in the sensory properties of our samples could be justified by the fact that, only grape pomace skins, wheat flour and eggs were used in the pasta formulation, without addition of water as in the classic recipe, which did not allow the breaking of the pasta. Thus, there was not affected the structure of pasta during the technological process as well as during boiling. It has been shown that the addition of gluten-free flour to the pasta recipe decreases the strength of the gluten and weakens the structure of the pasta with a negative effect on sensory properties (RAYAS-DUARTE
$\&$ al [34]). In our study, at a level of $9 \%$ GPS in the pasta recipe, there were occurred difficulties during pasta processing, especially during kneading, modeling and drying. These findings could be assigned to decreasing in the gluten content that led to a reduction of the dough elasticity. Also, the hydration capacity of the dough has been different as a result of the changes in the pasta recipe. Accepting the taste of fortified pasta depends on consumer education, by understanding that the incorporation of GPS provides high amounts of available polyphenols in the product matrix, with important health benefits.

Table 3. The total score and rating resulted from sensory analysis of pasta formulas

\begin{tabular}{|c|c|c|}
\hline Sample & Total score & Quality level \\
\hline C & $17.2 \pm 0.30$ & Good \\
\hline P+3\%PN & $18.9 \pm 0.46^{* *}$ & Very good \\
\hline P+6\%PN & $18.5 \pm 0.30^{*}$ & Very good \\
\hline P+9\%PN & $16.5 \pm 0.36^{\text {ns }}$ & Good \\
\hline P+3\%IR & $19.6 \pm 0.50^{* * *}$ & Very good \\
\hline P+6\%IR & $19.0 \pm 0.56^{* *}$ & Very good \\
\hline P+9\%IR & $15.8 \pm 0.26^{*}$ & Good \\
\hline
\end{tabular}

Statistical differences are indicated in a column, versus the control sample, as follows: ns - non-significant, $\mathrm{P}>0.05 ;{ }^{*}$ - significant, $\mathrm{P}<0.05 ;{ }^{* *}$ - highly significant, $\mathrm{P}<0.01$ and $^{* * *}-$ extremely significant, $\mathrm{P}<0.001$.

From the ANOVA analysis it could be noticed that the addition of GPS derived from RI at a level of $3 \%$ induced extremely significant changes $(\mathrm{P}<0.001)$ of sensory attributes versus the control sample. There were recorded highly significant differences $(\mathrm{P}<0.01)$ in the pasta samples with $3 \% \mathrm{PN}$ and $6 \% \mathrm{RI}$, versus the control sample. Also, the incorporation of GPS from PN at a level of $6 \%$ induced only significant changes $(\mathrm{P}<0.05)$ versus the control. As it can be seen from the Table 3 , the pasta formulas with GPS at a level of $9 \%$ showed slightly lower sensorial features than the control sample. Thus, the changes of sensory properties recorded by addition of GPS from IR were statistical significant $(\mathrm{P}<0.05)$, while those recorded in the pasta sample with GPS from PN have not shown any statistical significance $(\mathrm{P}>0.05)$

\section{Conclusion}

Our results reveal that the incorporation of GPS into the pasta formulas led to important increases of the total polyphenol content depending on the percentage used in the production recipe. A high positive correlation was detected between FRAP values and TP content of pasta samples, suggesting that the antioxidant capacity of the fortified pasta formulas increased due to the incorporation of polyphenols coming from GPS. Also, it was found that the improvements of TP content and FRAP values have been higher in pasta formulas with addition of GPS coming from IR than in the samples with GPS from PN. This finding could be attributed to the differences of winemaking processes used for white and black grapes. Our study reveals that the incorporation of GPS into the pasta formulation up to a level of $6 \%$ led to obtaining of products with improved organoleptic attributes and functional properties. A level of $9 \%$ GPS is not recommended in the pasta recipe because of the difficulties that could occur in the pasta processing, especially during kneading, modeling and drying as a result of decreasing in the gluten content and consequently, in the reduction of the dough elasticity. Therefore, the obtained data are useful to develop new pasta formulas with improved functionality by exploiting the potential of underused winery by-products.

\section{Acknowledgements}

This study was funded by a PhD Research Fellowship from the Doctoral School Engineering of Vegetal and Animal Resources at the Banat's University of Agricultural Sciences and Veterinary Medicine "King Michael I of Romania" from Timisoara and the results will be included in the PhD Thesis of Cristina Gaita. Also, this research has been carried out with the support of the Interdisciplinary Research Platform, belonging to the University of Agricultural Sciences and Veterinary Medicine of "King Michael I of Romania" from Timisoara.

\section{References}

1. Y. SUI, J. YANG, Q. YE, H. Li, H. WANG. Infrared, convective, and sequential infrared and convective drying of wine grape pomace. Drying Technol, 32(6): 686-694 (2014).

2. I.I. ROCKENBACH, E. RODRIGUES, L.V. GONZAGA, V. CALIARI, M.I. GENOVESE, A.E. DE SOUZA SCHMIDT GONCALVES, R. FETT. Phenolic compounds content and antioxidant activity in pomace from selected red grapes (Vitis vinífera L. and Vitis labrusca L.) widely produced in Brazil. Food Chem, 127: 174-179 (2011).

3. A. TEIXEIRA, N. BAENAS, R. DOMINGUEZPERLES, A. BARROS, E. ROSA, D.A. MORENO, C. GARCIA-VIGUERA. Natural bioactive compounds from winery by-products as health promoters: A Review. Int. J. Mol. Sci, 15(9): 15638-15678 (2014). 
4. E.W. FLAGG, R.J. COATES, R.S. GREENBERG. Epidemiologic studies of antioxidants and cancer in humans. J. Am. Coll. Nutr, 14(5): 419-427 (1995).

5. F.J. HE, G.A. MAC GREGOR. Beneficial effects of potassium on human health. Physiol. Plant, 133: 725-735 (2008).

6. J.L. SLAVIN. Position of the American Dietetic Association: health implications of dietary fiber. J. Am. Diet Assoc, 108(10): 1716-1731 (2008).

7. J. GARCÍA-LOMILLO, M.L. GONZÁLEZ-SANJOSE. Applications of wine pomace in the food industry: approaches and functions. Comp. Rev. Food Sci. Food Saf, 16(1): 3-22 (2017).

8. S. MILDNER-SZKUDLARZ, R. ZAWIRSKA-WOJTASIAK, A. SZWENGIEL, M. PACYNSKI. Use of grape by-product as a source of dietary fibre and phenolic compounds in sourdough mixed rye bread. Int. J. Food Sci. Technol, 46(7): 1485-1493 (2011).

9. A. BAIANO, I. VIGGIANI, C. TERRACONE, R. ROMANIELLO, M.A. DEL NOBILE. Physical and sensory properties of bread enriched with phenolic aqueous extracts from vegetable wastes. Czech J. Food Sci, 33(3): 247-253 (2015).

10. S. MANER., A.K. SHARMA, K. BANERJEE. Wheat flour replacement by wine grape pomace powder positively affects physical, functional and sensory properties of cookies. Proc. Natl. Acad. Sci. India Sect. B Biol. Sci, 87(1): 109-113 (2017).

11. M.U. ROSALES SOTO, K. BROWN, C.F. ROSS. Antioxidant activity and consumer acceptance of grape seed flour-containing food products. Int. J. Food Sci. Technol, 47(3): 592-602 (2012).

12. O.B. OPREA, L. APOSTOL, S. BUNGAU, G. CIOCA, A.D. SAMUEL, M. BADEA, L. GACEU. Researches on the chemical composition and the rheological properties of wheat and grape epicarp flour mixes. Rev. Chim, 69(1): 70-75 (2018).

13. V. LAVELLI, P.S.C. SRI HARSHA, L. TORRI, G. ZEPPA. Use of winemaking by-products as an ingredient for tomato puree: the effect of particle size on product quality. Food Chem, 152: 162-168 (2014).

14. B. RIBEIRO, C. CARDOSO, HA. SILVA, C. SERRANO, C. RAMOS, P.C. SANTOS, R. MENDES. Effect of grape dietary fibre on the storage stability of innovative functional seafood products made from farmed meagre (Argyrosomus regius). J. Food Sci. Technol, 48(1): 10-21 (2013).

15. A.E.D. BEKHIT, V.J. CHENG, M. MCCONNELL, J.H. ZHAO, R. SEDCOLE, R. HARRISON. Antioxidant activities, sensory and anti-influenza activity of grape skin tea infusion. Food Chem, 129: 837-845 (2011).

16. C. CAPPA, V. LAVELLI, M. MARIOTTI. Fruit candies enriched with grape skin powders: physicochemical properties. LWT - Food Sci. Technol, 62(1): 569-575 (2015).

17. A. TSENG, Y. ZHAO. Wine grape pomace as antioxidant dietary fibre for enhancing nutritional value and improving storability of yogurt and salad dressing. Food Chem, 138: 356-365 (2013).

18. I. SANCHEZ-ALONSO, A. JIMENEZ-ESCRIG, F. SAURA-CALIXTO, A.J. BORDERIAS. Antioxidant protection of white grape pomace on restructured fish products during frozen storage. LWT-Food Sci. Technol, 41(1): 42-50 (2008).

19. T.M. RABABAH, K. OVER, N.S. HETTIARACHCHY, R. HORAX, S. ESWARANANDAM, B. DAVIS, J. DICKSON, S. NIEBUHR. Infusion of plant extracts during processing to preserve quality attributes of irradiated chicken breasts over 9 months storage at $-20^{\circ} \mathrm{C}$. J. Food Process Preserv, 34: 287-307 (2010).

20. S. CHILlO, J. LAVERSE, P.M. FALCONE, A. PROTOPAPA, A., M.A. DEL NOBILE. Influence of addition of buckwheat flour and durum wheat bran on spaghetti quality. J. Cereal Sci, 47(2): 144-152 (2008)

21. V. SANT'ANNA, F.D.P. CHRISTIANO, L.D. FERREIRA MARCZAK, I.C. TESSARO, R.C. SILVEIRA THYS. The effect of the incorporation of grape marc powder in fettuccini pasta properties. LWT - Food Sci. Technol, 58(2): 497-501 (2014).

22. V. MARINELLI, L. PADALINO, D. NARDIELLO, M.A. DEL NOBILE, A. CONTE. New approach to enrich pasta with polyphenols from grape marc. J. Chem., 2015, Article ID 734578, 8 pages, doi:10.1155/2015/734578 (2015).

23. E.S. ABDEL-HAMEED, S.A. BAZAID, M.S. SALMAN. Characterization of the phytochemical constituents of taif rose and its antioxidant and anticancer activities. Biomed. Res. Int, 2013, Article ID 345465, 13 pages, doi:10.1155/2013/345465 (2013).

24. V.L. SINGLETON, R. ORTHOFER, R.M. LAMUELARAVENTOS. Analysis of total phenols and other oxidation substrates and antioxidants by means of FolinCiocalteu reagent. Methods Enzymol, 299: 152-178 (1999).

25. I.F.F. BENZIE, L. STRAIN. Ferric reducing ability of plasma (FRAP) as a measure of antioxidant power: the FRAP assay. Anal. Biochem, 239: 70-76 (1996).

26. M.A POIANA, D. MOIGRADEAN, D. DOGARU, C. MATEESCU, D. RABA, I. GERGEN. Processing and storage impact on the antioxidant properties and color quality of some low sugar fruit jams. Rom. Biotech. Lett, 16(5): 6504-6512 (2011).

27. STAS 756/1-85, Flour paste ware. General technical quality requirements, Collection of branch standards for the milling and bakery industry. Bucharest Organizing and Computer Center, 2: 450-455 (1989).

28. SAS Institute Inc. SAS for Windows, Version 8.1 Edition. Cary, North Carolina: SAS Institute Inc (2000).

29. S.EI GENGAIHI, F.M.A. ELLA, M.H. EMAD, E. SHALABY, H. DOHA. Antioxidant activity of phenolic compounds from different grape wastes. J. Food Process. Technol, 5(2): 5 pages, doi:10.4172/2157-7110.1000296 (2014).

30. L.M. RAMIREZ-LOPEZ, C.A.M. DEWITT. Analysis of phenolic compounds in commercial dried grape pomace by high-performance liquid chromatography electrospray ionization mass spectrometry. Food Sci. Nutr, 2(5): 470477 (2014)

31. M. SWIECA, U. GAWLIK-DZIKI, L. SECZYK. Changes of antioxidant potential of pasta fortified with parsley (Petroselinum Crispum Mill.) leaves in the light of protein-phenolics interactions. Acta Sci. Pol. Technol. Aliment, 14(1): 29-36 (2015).

32. Q. DENG, M.H. PENNER, Y. ZHAO. Chemical composition of dietary fiber and polyphenols of five different varieties of wine grape pomace skins. Food Res. Int, 44(9): 2712-2720 (2011).

33. Y. XU, S. BURTON, C. KIM, E. SISMOUR. Phenolic compounds, antioxidant, and antibacterial properties of pomace extracts from four Virginia-grown grape varieties. Food Sci. Nutr, 4(1): 125-133 (2016).

34. P. RAYAS-DUARTE, C.M. MOCK, L.D. SATTERLEEI Quality of spaghetti containing buckwheat, amaranth and lupin flours. Cereal Chem, 73(3): 381-387 (1996). 